\title{
Reliability algorithms applied to reinforced concrete structures durability assessment
}

\section{Algoritmos de confiabilidade aplicados para avaliação da durabilidade de estruturas em concreto armado}
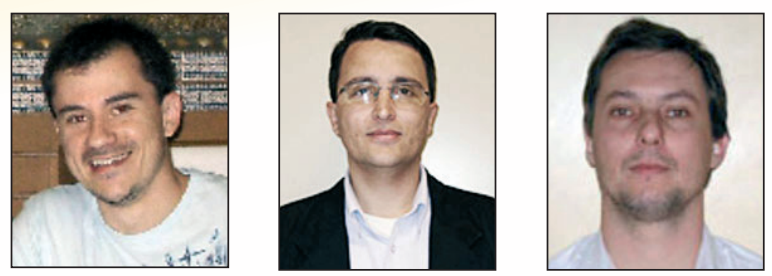

C. G. NOGUEIRA gorlanog@sc.usp.br

E. D. LEONEL edleonel@sc.usp.br

H. B. CODA ${ }^{c}$ hbcoda@sc.usp.br

\begin{abstract}
This paper addresses the analysis of probabilistic corrosion time initiation in reinforced concrete structures exposed to ions chloride penetration. Structural durability is an important criterion which must be evaluated in every type of structure, especially when these structures are constructed in aggressive atmospheres. Considering reinforced concrete members, chloride diffusion process is widely used to evaluate the durability. Therefore, at modelling this phenomenon, corrosion of reinforcements can be better estimated and prevented. These processes begin when a threshold level of chlorides concentration is reached at the steel bars of reinforcements. Despite the robustness of several models proposed in the literature, deterministic approaches fail to predict accurately the corrosion time initiation due to the inherently randomness observed in this process. In this regard, the durability can be more realistically represented using probabilistic approaches. A probabilistic analysis of ions chloride penetration is presented in this paper. The ions chloride penetration is simulated using the Fick's second law of diffusion. This law represents the chloride diffusion process, considering time dependent effects. The probability of failure is calculated using Monte Carlo simulation and the First Order Reliability Method (FORM) with a direct coupling approach. Some examples are considered in order to study these phenomena and a simplified method is proposed to determine optimal values for concrete cover.
\end{abstract}

Keywords: reliability algorithms, durability, reinforced concrete, concrete cover.

\section{Resumo}

Este artigo aborda a análise probabilística do tempo de início da corrosão em estruturas de concreto armado expostas à penetração de íons cloretos. Durabilidade estrutural é um critério importante que deve ser avaliado em cada tipo de estrutura, especialmente quando estas estruturas são construídas em ambientes agressivos. Considerando os elementos em concreto armado, o processo de difusão de cloreto é amplamente utilizado para avaliar a durabilidade. Dessa forma, com a modelagem deste fenômeno, a corrosão das armaduras pode ser mais bem estimada e evitada. Estes processos começam quando um nível limite de concentração de cloretos é alcançado nas barras de aço da armadura. Apesar da robustez dos vários modelos propostos na literatura, as abordagens determinísticas não conseguem prever com precisão o tempo de início de corrosão, devido à aleatoriedade inerentemente aos parâmetros que controlam este processo. A este respeito, a durabilidade pode ser representada de forma mais realista utilizando abordagens probabilísticas. Uma análise probabilística da penetração de íons cloreto é apresentada neste artigo. A penetração de íons cloreto é simulada usando a segunda lei de Fick da difusão. Esta lei representa o processo de difusão de cloreto, considerando efeitos dependentes do tempo. A probabilidade de falha é calculada usando simulação de Monte Carlo e o Método de Confiabilidade de Primeira Ordem (FORM) com uma abordagem via acoplamento direto. Alguns exemplos são considerados, a fim de estudar estes fenômenos e um método simplificado é proposto para determinar os valores ótimos para o cobrimento de concreto.

Palavras-chave: algoritmos de confiabilidade, durabilidade, concreto armado, cobrimento de concreto.

School Engineering of São Carlos, Department of Structural Engineering, University of São Paulo, PhD, gorlanog@sc.usp.br, Av. Trabalhador Sãocarlense 400, Zip Code 13560-000, São Carlos-SP, Brazil;

b School Engineering of São Carlos, Department of Structural Engineering, University of São Paulo, Professor, edleonel@sc.usp.br, Av. Trabalhador Sãocarlense 400, Zip Code 13560-000, São Carlos-SP, Brazil;

School Engineering of São Carlos, Department of Structural Engineering, University of São Paulo, Titular professor, hbcoda@sc.usp.br,

Av. Trabalhador Sãocarlense 400, Zip Code 13560-000, São Carlos-SP, Brazil; 


\section{Introduction}

Concrete structures, especially reinforced concrete structures, are one of most used types of structures around world. When it is located in non aggressive environments, these types of structures respect, in general, its structural life predicted, which is given by the durability criteria. Regarding durability, it can be measured as a period of time in which the structure maintains, at least, minimal functional conditions, resistance and external aspects required in design. However, the structural durability can be strongly affected by degradation processes of environmental and/or functional origins [1,2]. Among these processes, it is worth to mention the penetration of chlorides, carbonation, fatigue and creep. Therefore, reinforced concrete design with reliability analysis for structural durability as well as prediction of repairs and maintenance has becoming increasingly accepted [3-5].

One of the most important degradation processes in reinforced concrete structures is the reinforcement corrosion phenomenon. It is directly responsible for the durability and failure of concrete structures. With respect to the external agents, chloride diffusion is identified as one of the major factors that cause reinforcement corrosion. When corrosion begins, the durability of the structure is affected by several phenomena like reduction of the reinforcement's cross section, bursting of concrete and adherence loss between steel and concrete $[6,7]$.

In general, the corrosion process can be divided into two stages: the initiation and the propagation period. During the initiation period, chloride ions diffuse through concrete toward the reinforcements. The chloride concentration reaches a threshold value, which triggers the corrosion of steel. The propagation period of the corrosion process is defined as the time from the start of corrosion to a critical steel loss limitation being reached. Compared with the first stage, the propagation period is relatively short. Therefore, the chloride diffusion process is frequently used to indicate the durability and service life of concrete structures [8].

Regarding the prediction models for those corrosion times, several models have been proposed in the literature to deal properly with the corrosion phenomenon in reinforced concrete structures. Most of them propose deterministic approaches in order to modelling this structural problem. However, due the large number of inherent uncertainties, as the penetration of chlorides in concrete, these problems can only be accurately analyzed considering probabilistic approaches. Among these models and formulations, it is worth to mention [9-13], where the corrosion process was studied considering several conditions and variables. Based on these probabilistic models, life assessment analysis in reinforced concrete structures exposed to chloride penetration can be accurately performed [14-16]. For example, considering these results, aspects of maintenance and inspection plans, an optimal structural concrete cover can be proposed taking into account the randomness inherent of the variables in each model regarding the involved cost on each procedure.

In order to achieve the durability requirements in reinforced concrete design, a mechanical model to evaluate the chloride concentration at every position inside concrete is needed. Moreover, the chloride penetration mechanism is controlled by complexes interactions among physical and chemical mechanisms, which are a large source of uncertainties. However, this phenomenon is often simplified, without significant loss, by problems controlled only by diffusion process.

Fick's diffusion laws have all the requirements to modelling the problem and it is based in some hypotheses such as: concrete is an homogeneous material in space; a direct consequence of this assumption is a constant value for the coefficient of diffusion along time; the model supposes that concentration of ions chloride in the environment is constant and it admits the concrete in saturated condition. Assuming all these behaviours, probabilistic analyses of chloride ingress in concrete structures can be performed by coupling Fick's diffusion laws with reliability algorithms.

In this paper, a coupled mechanical and reliability model is developed in order to allow probabilistic analyses of reinforced concrete structures subjected to ions chloride ingress. These analyses aim at quantifying the probability of corrosion start in reinforced concrete structure based on a reliability approach. The mechanical model is based on the Fick's second diffusion law, which is capable to simulate the chloride penetration process in porous materials. Then, the chloride concentration at a given concrete cover depth and the respective time can be evaluated. In order to determine the probability of failure, two reliability algorithms were considered: direct coupling of mechanical model with FORM and Monte Carlo simulation. Both algorithms determine the probability of failure considering the failure scenarios achieved by the mechanical model based on Fick's diffusion law. The probabilistic chloride penetration is analyzed for some particular cases and the set of values achieved by the proposed models are discussed. A simplified procedure to obtain the optimal concrete covers for periodic inspections is also illustrated by the building of some abacuses.

\section{The mechanical model - Fick's diffusion law}

Corrosion of reinforcements induced by chlorides can take place in the presence of oxygen and moisture when the chloride build-up within the structures exceeds a threshold value. Even for a carefully constructed concrete, with negligible or practically non chloride inherited at the construction stage, the gradual build-up of the required level of chloride content to initiate corrosion of reinforcement takes place slowly through ingress of chloride ions from external sources.

The transport phenomenon associated with the movement of chloride ions along structures exposed to aggressive environments is attributed mostly to diffusion of chloride ions into concrete porous under a concentration gradient. Chloride diffusion coefficient of concrete, which depends upon the pore structure of the concrete, characterizes this flow under a given concentration of chloride exposure and it is considered as a characteristic property of a hardened concrete.

In order to simulate the chloride ingress and its transport into the concrete porous, Fick's second law of diffusion [17] has been widely considered as an acceptable model. The Fick's laws for diffusion are applicable for material homogeneous, isotropic and inert [18]. Moreover, the mechanical properties of diffusion process are assumed to be the same along all directions and kept constants along time. Considering concrete, these hypotheses are not completely satisfied because concrete is well known as heterogeneous, anisotropic and chemically reactive (continued hydration and micro- 
-cracking process) material. However, the methods commonly adopted for chlorides transportation modelling in concrete consider this process governed only by ionic diffusion, then, it assumes that the concrete cover is completely saturated. Therefore, it makes the Fick's laws hypotheses acceptable for the chloride ingress modelling, because, in this case, the material is assumed completely saturated, with unidirectional chloride flux, i.e., from the exterior surface into the concrete depth. When chloride diffuses into concrete, a change of chloride concentration occurs at any time in every point of the concrete, i.e., it is a non-steady state of diffusion. In order to simplify its analysis, the diffusion problem is considered as one-dimensional. Many engineering problems of chloride ingress, as those discussed in this paper, can be solved considering this simplification.

The assumption of Fick's diffusion theory is that the transport (given by the flux) in concrete of chloride ions though a unit section area of concrete per unit of time is proportional to the concentration gradient of chloride ions measured normally to the section. Then:

$$
F=-D \frac{\partial C}{\partial p}
$$

in which: $F$ is the flux of ions chloride into concrete, $D$ is the general coefficient of diffusion of the concrete, $C$ corresponds to the chloride concentration at any position inside concrete, $p$ is the such position.

The negative sign in the equation above arises because the diffusion of chloride ions occurs in the opposite direction of the concentration increasing of chlorides ions. In general, $D$ is not constant, but depends on many parameters as the time for which diffusion has taken place, location in the concrete, composition of the concrete, among other factors. If the chloride diffusion coefficient is constant, equation (1) is usually referred as Fick's first diffusion law. If this is not the case, the relation is usually referred as Fick's first general diffusion law.

There are some cases where this simple relation should not be applied. In this regard, it is worth to mention the cases where the diffusion process may be irreversible or has a history-dependence. In such cases, Fick's diffusion law is not valid and the diffusion process is referred as anomalous. However, none observation so far indicates that the chloride diffusion in concrete should be characterized as an anomalous diffusion. The Fick's second law can be derived considering the mass balance principle. Then:

$$
\frac{\partial C}{\partial t}=\frac{\partial}{\partial p}\left(-D \frac{\partial C}{\partial p}\right)
$$

In order to apply Fick's second diffusion law, in this form, for concrete exposed to chloride during a long period of time, one ought to know the variation of the chloride diffusion coefficient along time. If only few observations exist in a specific case, it is possible to estimate upper and lower boundary for the variation of $D$ in time. Despite this dependence, an especial case can be considered where the chloride diffusion coefficient is independent of location, time and the chloride concentration. In this case, Fick's second law can be rewritten in the simpler form:

$$
\frac{\partial C}{\partial t}=D_{0} \frac{\partial^{2} C}{\partial p^{2}}
$$

in which: $D_{0}$ is the constant chloride diffusion coefficient of concrete, $t$ is the time of the assessment of chloride concentration.

The solution of the differential equation (3), for a semi-infinite domain with an uniform concentration at the structural surface, is given by:

$$
C(p, t)=C_{0} \operatorname{erfc}\left[\frac{p}{2 \sqrt{D_{0} t}}\right]
$$

in which: $C_{0}$ is the ions chloride concentration at the structural surface supposed constant in the time, erfc is the complementary error function.

In this paper, equation (4) is used to evaluate the chloride concentration $C(p, t)$, at a given position $p$ and time $t$, and for that reason is also used as the mechanical model in this paper. Based on the concentration values of chloride ions at a given structural depth, it is possible to assess the structural safety. However, in order to allow the safety assessment, a coupling among the described mechanical model and reliability algorithms has been constructed. These coupling models take into account the inherent randomness of the variables in the diffusion process. One of the most important product of these coupling is the possibility to choose the critical time of structural maintenance based in a given target reliability index or the determination of the concrete cover depth based on the structural safety level target.

\section{Reliability concepts and methods of analysis}

\subsection{General concepts}

The reliability analysis aims at computing the probability of failure regarding a specific failure scenario, known as limit state. The first step in the reliability assessment is fo identify the basic set of random variables $X=\left[x_{1}, x_{2}, \ldots, x_{n}\right]^{T}$ for which uncertainties have to be considered. For all these variables, probability distributions are attributed in order to model its randomness. These probability distributions can be defined by physical observations, statistical studies, laboratory analysis and expert opinion. The number of random variables is an important parameter to determine the computing time consumed during the reliability analysis. In order to reduce the size of the random variable space, it is strongly recommended to consider as deterministic all variables whose uncertainties lead to minor effects on the value of probability of failure.

The second step consists in defining a number of potentially critical failure modes. For each of them, a limit state function, separates the space into two regions as described in figure 1: the safe domain, where $G(X)>0$ and the failure domain where $G(X)<0$. The boundary between these two domains is defined by $G(X)=0$, 


\section{Figure 1 - Domains of failure and safety for two random variables}

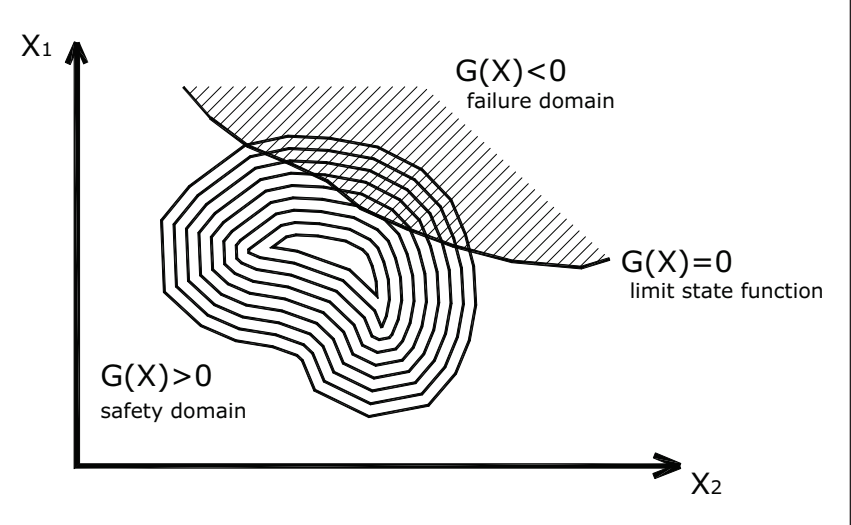

known as the limit state itself. It is worth to mention that an explicit expression of the limit state function is usually not possible. When numerical mechanical models are used, only at a desired number of points it can be computed. In this paper, the limit state is defined using the critical failure mode calculated by equation (4).

The probability of failure is evaluated by integrating, over the failure domain, the joint density function as presented by [19]:

$$
P_{f}=\int_{G \leq 0} f_{X}\left(x_{1}, x_{2}, \ldots, x_{n}\right) d x_{1}, d x_{2}, \cdots d x_{n}
$$

in which: $f_{X}(X)$ is the joint density function of the random variables $X$.

As the evaluation of integral defined by equation (5) is almost impossible in practice, alternative procedures have been developed on the basis of reliability index concept [20]. This parameter is defined by the distance between the mean point and the failure point placed at the limit state function $G(X)=0$ in the normalized space of random variables. The reliability index allows us to calculate the probability of failure, using the First Order Reliability Method (FORM) as follow:

$$
P_{f}=\Phi(-\beta)
$$

in which: $\Phi(\cdot)$ is the standard Gaussian cumulated distribution function, $\beta$ is the reliability index.

There are some alternative procedures, available in the reliability theory, which allow the probabilities assessment of structural failure. These procedures are based on numerical simulation techniques. The most important approach, among them, is the Monte Carlo's simulation method. However, when numerical mechanical models expensive in terms of computational work are adopted, this approach may be unreliable, due the large sampling required for simulation. In this study, two reliability approaches are adopted. The first is known as direct approach, as it is the result of direct coupling a mechani- cal model at the First Order Reliability Method (FORM). The second approach used is the classical Monte Carlo's simulation. In both cases, the models are used to evaluate the probabilities of failure considering the chloride ingress process, in reinforced concrete structures. These approaches will be discussed in the following sections.

\subsection{Direct approach - mechanical model and FORM}

The basic procedure in this model consists in directly coupling the reliability model FORM with the mechanical model given by equation (4). This approach has demonstrated be accurate and robust for analysis of many complex engineering problems, as discussed by [21-23].

As described in the previous section, the limit state function defines the boundary between safe and failure domains. Considering chloride penetration problem, the limit state function can be written in terms of the time for corrosion initiation:

$$
G(X)=t_{R}(X)-t_{a}
$$

in which: $t_{R}$ is the time for corrosion initiation that depends of the set of random variables $X ; t_{a}$ is the structural life-time expected in design which was considered as a deterministic parameter or it can be the suggested time for inspections.

The time $t_{R}$ is evaluated from equation (4) assuming the chloride concentration $C(p, t)$ as known at a given position $p$ inside the concrete. Actually, $C(p, t)$ is assumed to be equal to the chloride concentration threshold value, over which the steel corrosion is triggered, in failure condition. The range of $p$ position, in this case, is the concrete cover, in which it assumes zero at the external surface of the structural member and the cover value at the reinforcement surface inside concrete. In this regard, the time for corrosion initiation can be determined explicitly from equation (4) as:

$$
t_{R}=\frac{1}{D_{0}}\left\{\frac{p}{2 \operatorname{erfc}\left[C(p, t) / C_{0}\right]}\right\}^{2}
$$

In order to include invariance measure of safety, the random variables, defined in the physical space, are transformed into independent standard Gaussian variables [20], by using appropriate probabilistic transformations. The limit state function $G(X)=0$, defined in the physical space, is transformed into $H(U)=0$ in the standard normalized space with $U=\left[u_{1}, u_{2}, \ldots, u_{n}\right]^{T}$, where $\mathrm{U}$ is the set of normalized random variables. In this standard space, the reliability index $\beta$ is given by the minimum distance between the failure domain and the origin of the standard space. The reliability index can be evaluated by solving a constrained optimization problem, as described below:

Find: $U$, which minimizes: $\beta=\sqrt{U^{T} \cdot U}$ and subject to:

Find: $U$, which minimizes: $\beta=\sqrt{U^{T} \cdot U}$ and subject to: $H(U)=0$ 


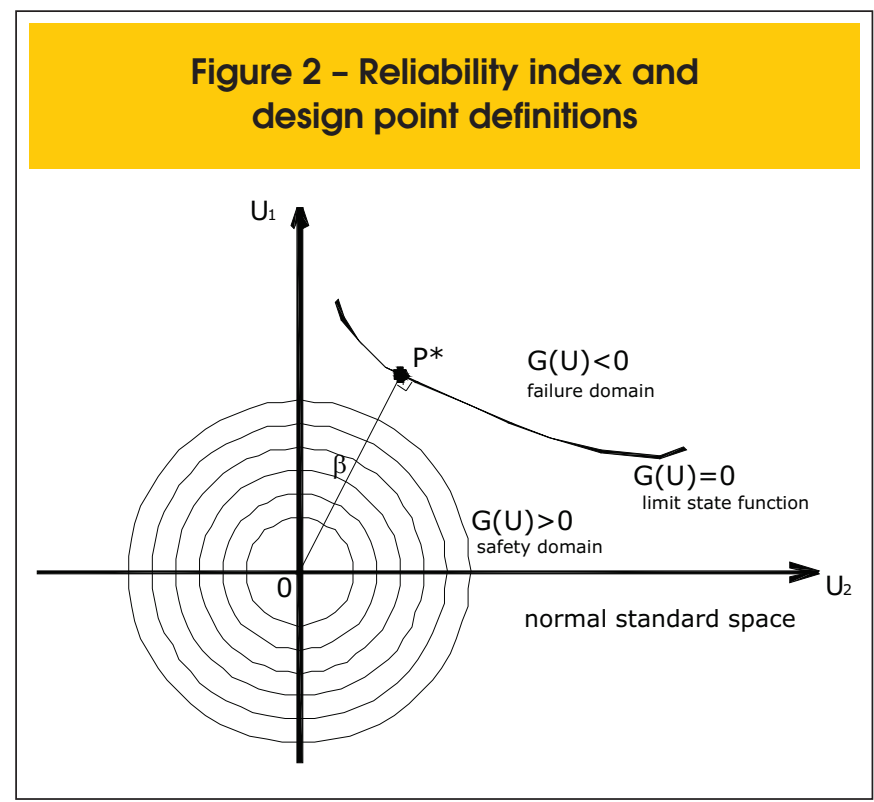

The solution of this problem converges to the failure point nearest to the space origin, known as design point or the most probable failure point $U^{*}$. In standard space, the distance between this point and the origin is the reliability index, as shown in figure 2 . The reliability index $\beta$ can be achieved by applying any optimization algorithm. A particular algorithm, which is efficient in this case, to solve reliability problems, is the HLRF algorithm [24]. This optimization algorithm can be coupled directly to the mechanical model. As the time for corrosion initiation is known point-by-point, the resistance $t_{R}$ is known. Consequently, the limit state function is determined point-by-point. Then, the gradient of the limit state function can be determined using any numerical procedure. In this paper, it was used the forward finite differences technique for this proposal.

Some difficulties may arise from equation (8), particularly its gradients

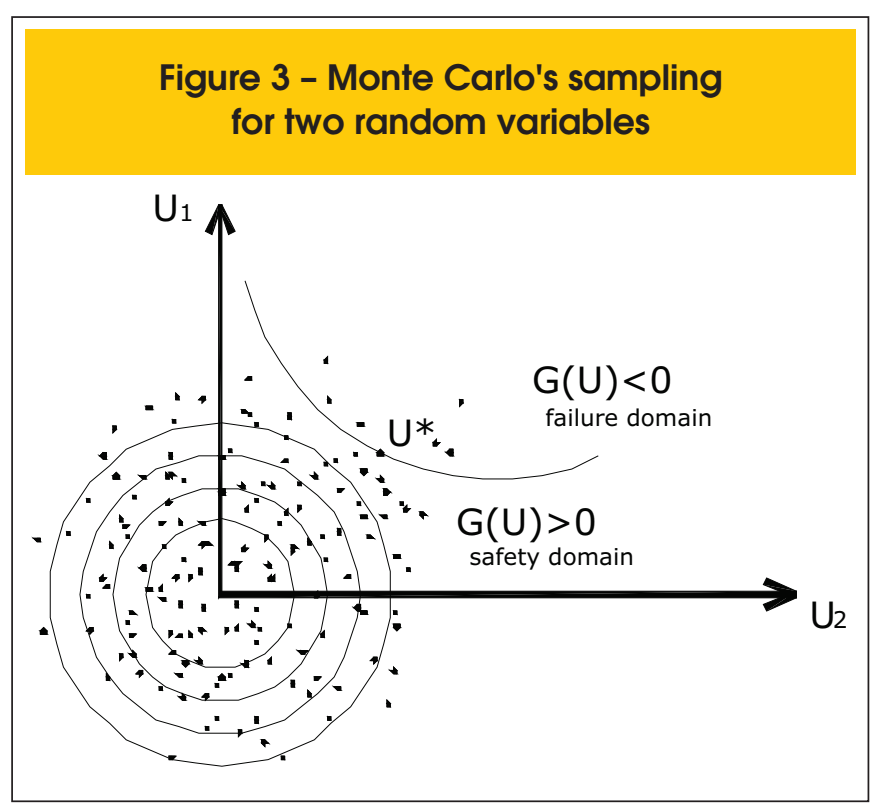

Figure 4 - Corrosion process of the reinforcement cross-section area

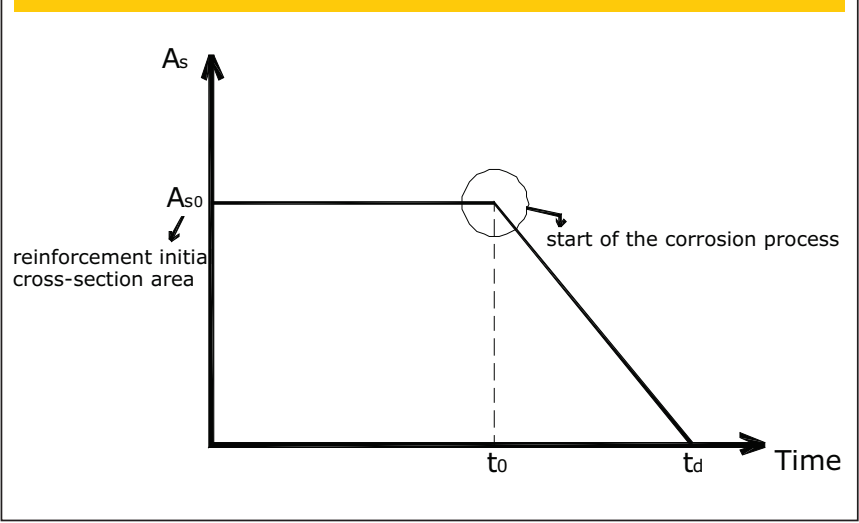

evaluation, due the presence of the error complementary function. A natural barrier that can be remarked in this type of approach is the numerical error due to finite difference procedure, which may affect the convergence of the coupled procedure, as well as the precision of the solution, especially for nonlinear transient phenomena. However, for all problems studied in this paper, numerical problems related to finite differences method were not observed. Moreover, it was verified that the direct coupling procedure gives accurate results and stable convergence rate with a reasonable number of mechanical analyses.

\subsection{Monte Carlo simulation}

Monte Carlo's method is a numerical simulation approach widely used in reliability problems [25]. In this method, a sampling of random variables is used to construct a set of values aiming to describe the failure and safe spaces and calculate equation (5). The sampling is constructed based on the statistical distribution assigned for each random variable in the problem. As this method deals with the simulation of the limit state function, as bigger be the sampling adopted more accurate will be the description of the space and more accurate will be the probability of failure achieved. The kernel of this method consists on the construction of a sampling for each random variable involved in the problem. Then, the domain of safety and failure points are prospected by simulating equation (7), as described in figure 3 . The probability of failure is calculated, for Monte Carlo's simulation, using the following expression:

$$
P_{f}=\int_{G \leq 0} f_{X}\left(x_{i}\right) d x_{i}=\int_{G \leq 0} I\left(x_{i}\right) f_{X}\left(x_{i}\right) d x_{i}=E\left[I\left(x_{i}\right)\right]
$$

The function $I\left(x_{i}\right)$ is a discrete operator to compute failures and it can be written as:

$$
I\left(x_{i}\right)=\left\{\begin{array}{l}
1 \rightarrow G \leq 0 \\
0 \rightarrow G>0
\end{array}\right.
$$


By simulating the limit state function for a convenient number of sampling, the mean value $(E)$ of $I\left(x_{i}\right)$ will be an estimator for the probability of failure. Then:

$$
\bar{P}_{f}=E\left[I\left(x_{i}\right)\right]=\frac{1}{N} \sum_{i=1}^{N} I\left(x_{i}\right)
$$

The disadvantage of this method is related to the large amount of simulations $N$ required to compute accurately the probability of failure. Normally, in order to estimate accurately the probability of failure of $10^{-n}$, the number of simulations must be higher than $10^{n+2}$ or $10^{n+3}$. It means, in civil engineering structures, where the probability of failure is in between $10^{-3}$ to $10^{-6}$, it is required, at least, $10^{5}$ to $10^{9}$ realizations of the limit state function. When complex numerical mechanical models are involved, which lead to high computational work, this method may be not reliable. However, theoretically, this method leads to the real probability of failure when the sampling range becomes infinity.

\section{Methodology of analysis}

The corrosion phenomenon modelling in reinforced concrete structures has to take into account two different stages, as illustrated in figure 4 . The first stage is related to chloride ingress into concrete porous. In this stage, the chloride concentration, along the cover depth, increases as the time passes. Then, the corrosion starts when the chloride concentration surrounding the reinforcements reaches a threshold level, leading to the loss of the concrete chemical passive protection. At the end of this stage the steel of reinforcements remains undamaged. The second stage, called propagation stage, is characterized by the reduction of the reinforcement's cross sections, which generates the loss of structural strength along the time.

Compared with the first stage, the propagation period is relatively short. Therefore, the time for corrosion initiation has been widely adopted for structural durability and safety assessments. In this regard, the objective of this paper is to assess the probability of failure considering the failure scenario predicted by initiation stage. Therefore, the failure is observed when the chloride concentration at the reinforcement's depth reaches the threshold level. In this regard, the main parameters considered for all reliability analyses performed are:

- Chloride concentration threshold at the interface between concrete and reinforcement bars, which defines the beginning of the corrosion process, $C(x, t)$. This parameter was studied experimentally by [12];

- Chloride concentration at the structural surface, $C_{0}$. This parameter is related to the environment aggressiveness and its reference's values may be determined by experimental observations, as presented by [12], or defined using an international concrete standard design code [26];

- Concrete diffusion coefficient, $D_{0}$, which has been studied by [27];

- Structural depth, which in this study, is defined as the reinforcement concrete cover, $p$

It is worth to stress that initial cracks due concrete cure and/or bending/shear effects and longitudinal cracking have not been consi- dered in the formulation presented in this paper. These phenomena affect the corrosion process and its modelling can be accurately performed using numerical methods as finite element method and boundary element method [28].

According [12], the chloride concentration at the structural surfaces is a function of the atmosphere (environment) where these elements are located. The cover depth is also defined according the environment, which is stated by international concrete standard design in categories of aggressiveness. In particular, the values shown in [26] have been used in this paper. The coefficient of diffusion of concrete, which represents the material resistance against chloride ingress, depends on the water/cement ratio. As higher be the proportion of water, higher will be the empty volumes inside the matrix due the cure process of the concrete. Consequently, higher will be the material permeability and lower will be the material resistance against the chloride penetration. Therefore, in regions close to the coast it is strongly recommended to construct reinforced concrete structures with lower water/cement ratio and/or large covers.

The proposed probabilistic model allows the evaluation of the probability of structural failure taking into account the random variables previously presented. Moreover, this model is capable to describe the dependency relation between the probability of failure and time. Then, the proposed model can be used to solve an interesting structural problem which is related to structural maintenance plans based on structural safety.

In order to apply the model in this problem a given safety level must be defined. The mentioned safety level may be determined using [29], where the prevention against structural failures is measured based on a target reliability index. As the chloride concentration at the structural cover increases along time, the safety against this failure mode reduces along time. Therefore, the intervals of time for periodic structural maintenance procedures, based on structural safety, are achieved when the reliability index calculated using the proposed model reaches the target reliability index stated by the analyst. It is worth to mention that the repair procedures are assumed, in this case, as perfect, i.e, after the maintenance the structure recover its initial integrity conditions without chlorides. These intervals are determined as long as the parameters related to material, cover depth and environment aggressiveness be defined a priori.

Another application of the proposed model relates the definition of values for cover depth and concrete properties, as for example water/cement ratio $(\mathrm{w} / \mathrm{c})$, based on a given safety level and the expected structural life-time. When the intervals of time for structural maintenance and/or the expected structural life-time are stated a priori, the $w / c$ ratio and the cover depth values can be obtained by simulating the proposed model in order to define the couple of these values which lead the structure to maintain a safety level at least equal to the target reliability index during the specified period of time. In this application the values of w/c ratio and cover depth are achieved when the reliability index given by the proposed model is equal to the target reliability index.

It is important to emphasize that, these procedures do not take into account the costs involved neither in the maintenance procedure nor in the concrete production. However, these applications of the proposed model can be performed if the analysts are interested in design considering, exclusively, safety criterion. 


\section{Figure 5 - Probability of failure versus time for C.A.II}

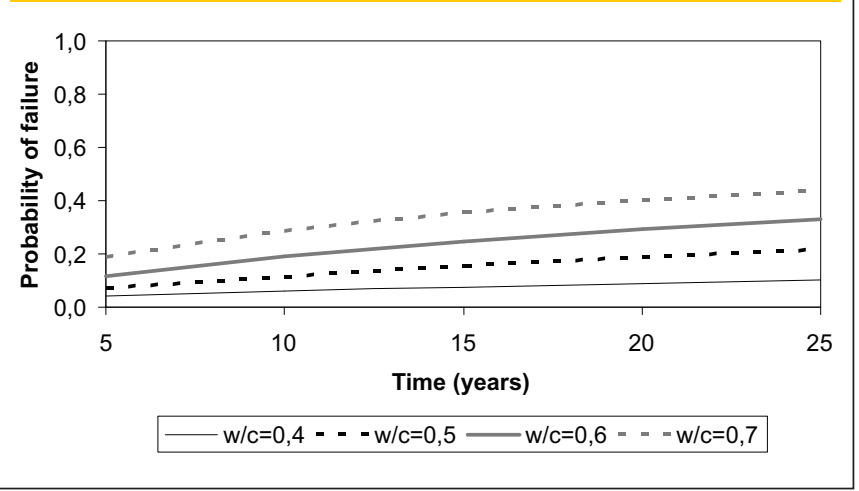

\section{Applications}

In order to illustrate the applicability of the proposed model, probabilistic analyses were performed considering different scenarios and material properties aiming to evaluate the influence of the environment aggressiveness, water/cement ratio and cover depth on the probability of structural failure due chloride penetration. Four applications are considered and in each of them some specific aspect of the problem are explored.

\subsection{Example 1}

In this example, the probabilistic model is applied at modelling the uncertainties related to chloride ingress in reinforced concrete structures. The results were obtained using direct method and Monte Carlo's simulation approaches. Considering direct method, the tolerance for convergence was verified in terms of reliability index and design point coordinates change, which ones have to be smaller than $10^{-4}$. It is worth to mention that considering this approach, only 65 limit state function runs were required in order to achieve the convergence. Moreover, this number of mechanical model runs is the highest observed among all scenarios considered. It confirms the good performance of direct method approach, which is capable to achieve the convergence with low computational work even in reliability problems involving non-Gaussian random variables and non-linear mechanical model. The analyses performed using Monte Carlo's simulation considered a sampling of $10^{5}$ values for each random variable. It leads to $10^{5}$ simulations of the limit state function. Table 1 presents the statistical parameters adopted for all random variables considered in this application, which are based on the work of $[12,16]$.

According [26], categories of aggressiveness (C.A.) II (moderate) and III (high) represent, respectively, urban regions and coast/industrial areas. For each one of these C.A., there is a recommended concrete cover depth, $p$, which was adopted for the probabilistic analyses of each category.

The evolutions of the probability of corrosion initiation along the time, for both categories of aggressiveness considered in this application, are presented in figure 5 and figure 6 . The results illustrate a considerable growth of the probability of corrosion initiation as the time increases. Moreover, it was also verified a strong dependency between the probability of corrosion initiation and the w/c ratio. This dependency was expected, because as higher be the w/c ratio, higher will be the concrete permeability and, consequently, easier is the chloride ingress.

Considering the horizon of time analyzed, for concretes with w/c ratio values higher than 0.50 , after 15 years of structural service life, the probability of failure tends to increase slower than in the first 15 years. Therefore, the derivative of the probability of corrosion initiation after 15 years is smaller than in the first 15 years. This behaviour reflects the chloride concentration evolution along time, which tends to saturation after 15 years. It is important to stress that this behaviour was observed in both C.A. analyzed.

\subsection{Example 2}

This application aims to study the influence of cover depth values on the probability of corrosion initiation considering two different scenarios of environment aggressiveness. The analyses were performed considering concretes composed by w/c ratio varying from 0.40 to 0.70 . The analyses involved cover depth in the range 10$60 \mathrm{~mm}$. For each value of $\mathrm{w} / \mathrm{c}$, the mean value of cover depth was also varied but its coefficient of variation was kept constant. This procedure was adopted because this study aims at describing the dependency of the probability of failure with respect to w/c and cover depth parameters. The time was assumed as deterministic in this analysis. In order to consider all the combinations, $240 \mathrm{nu}$ merical reliability analyses were carried out. The direct method and Monte Carlo's simulation were adopted for the evaluation of probability of failure and reliability indexes. Considering direct method, the convergence is assumed when the difference, in two successive iterations, in terms of reliability index and design point coordinates is smaller than $10^{-4}$. Considering Monte Carlo simulation, a sampling of $10^{5}$ values for each random variable was adopted.

The computational time consumed in this analysis is relatively lower. Considering direct method, the most expensive case required 65 limit state function calls, corresponding to less than 1 second of computational work. The Monte Carlo analyses required $10^{5}$ limit state function evaluation, due the sampling range adopted. However, it took less than 3 seconds of computational time process. The

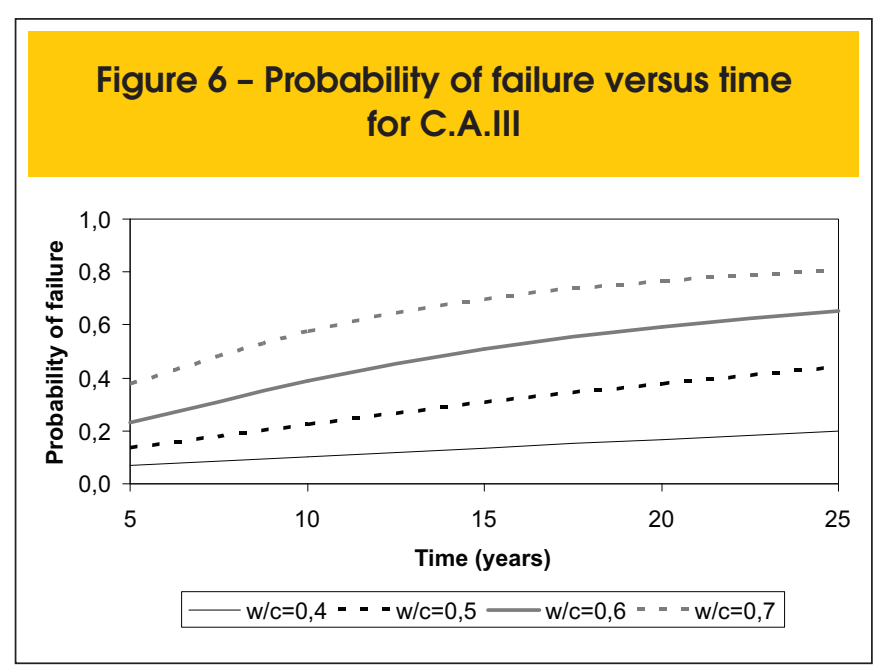


Figure 7 - Evolution for probability of corrosion initiation - C.A.II structural life-time $=5$ years

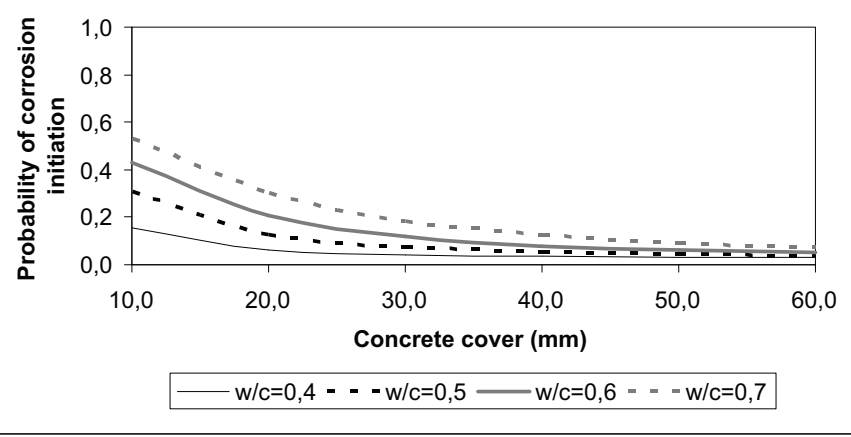

Figure 8 - Evolution for probability of corrosion initiation - C.A.II structural life-time $=15$ years

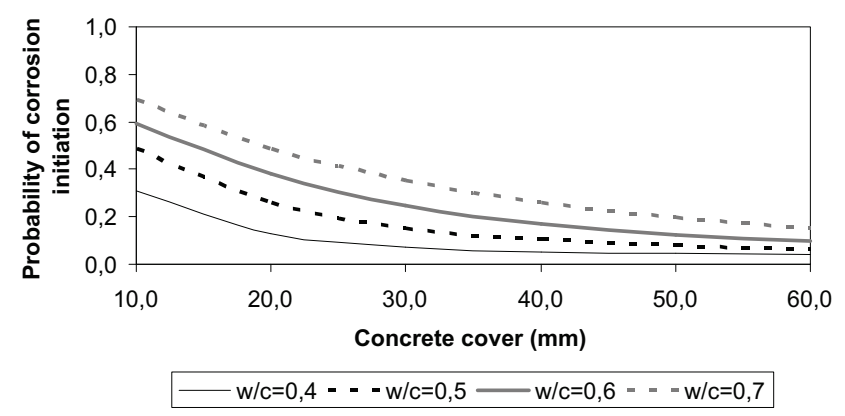

Figure 9 - Evolution for probability of corrosion initiation - C.A.Il structural life-time $=25$ years

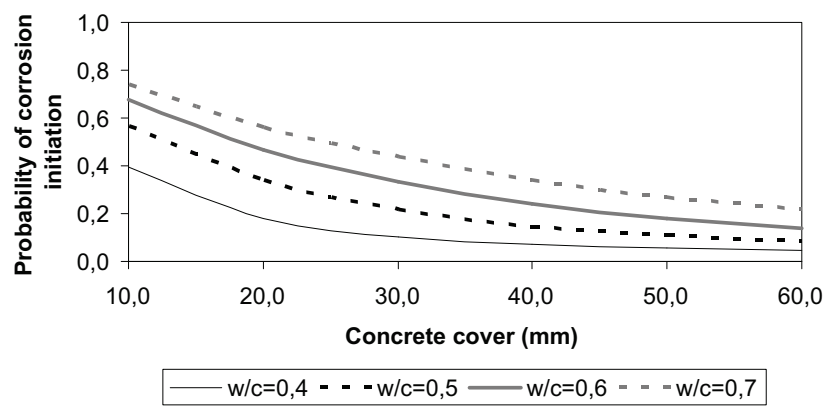

values adopted for all random variables considered in this application, as well its statistical information are presented in table 2, which are based on the work of $[12,16]$.

The evolution of probability of corrosion initiation in function of cover depth and w/c ratio, considering C.A. II, is presented in figures 7,8 and 9 . As presented in three figures above, the probability of corrosion initiation reduces faster when the cover thickness increases from 10 to $40 \mathrm{~mm}$. However, this reduction tends to stabilize when the cover depth is larger. Then, these results show that by increasing the cover thickness, an effective improvement on the structural safety is not observed from a certain value of depth. From this value, the structural cost grows faster than the structural safety against the corrosion initiation failure. However, this type of behaviour is different for each value of $\mathrm{w} / \mathrm{c}$ ratio adopted and the time considered. For concretes with low value of w/c 0.40 to 0.50 for instance, the stabilization process is faster observed than in permeable concretes, with w/c 0.60 or 0.70 . Considering permeable concretes, it is required thicker covers in order to achieve the stabilization on the reliability index value.

The analyses aiming the determination of the evolution of probability of corrosion initiation in function of cover depth and w/c ratio, involving C.A. III, are presented in figures 10, 11 and 12 .

The behaviour of the curves observed in these three last figures is similar to those presented for C.A. II. However, due the high environment aggressiveness, the probability of corrosion initiation tends to be higher than in C.A.II for the same structural life time and cover depth. The stabilization of the probability of corrosion initiation values, observed in previous analyses, also occurs for C.A.III. However, this process, for C.A. III, is observed for cover depth values thicker than in C.A.Il case.

Another important aspect that should be mentioned is the time dependency considered on time corrosion initiation analyses. As long is the time desired to avoid the corrosion initiation or even though to reduce the probability of corrosion initiation process, thicker

\section{Figure 10 - Evolution for probability of corrosion} initiation - C.A.III structural life-time $=5$ years

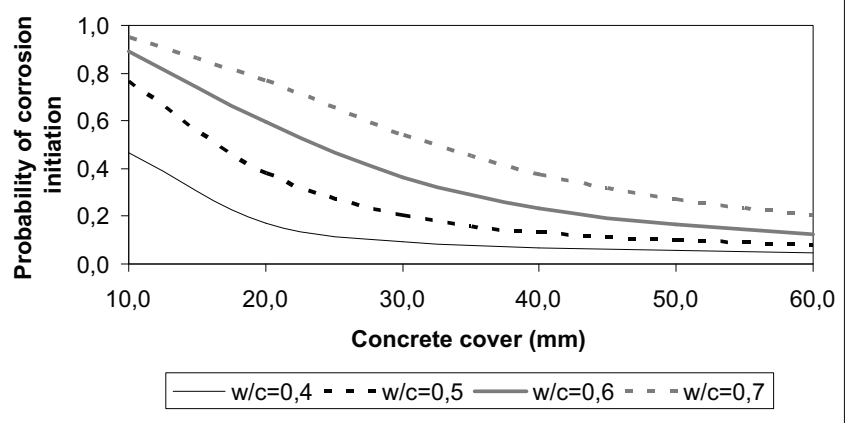

Figure 11 - Evolution for probability of corrosion initiation - C.A.III structural life-time $=15$ years

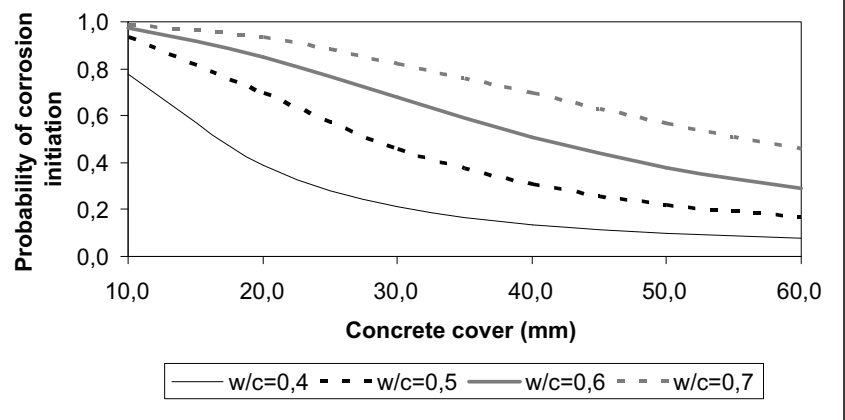


must be the covers adopted to reach the condition of reliability index stabilization. Thus, this type of analyses gives an interesting parameter which can be used to establish periods of structural maintenance according the type of concrete used and the environment where the structure is located.

\subsection{Example 3}

The proposed probabilistic model can be used to determine intervals of time in order to plan inspection and maintenance

\section{Figure 12 - Evolution for probability of corrosion initiation - C.A.III structural life-time $=25$ years}

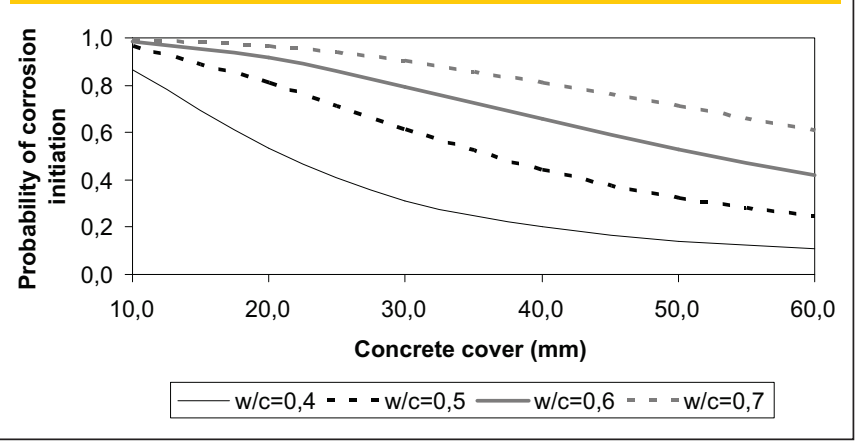

ties. It was considered two classes of aggressiveness, C.A. II and C.A. III. The abacuses involving reliability index, time and cover depth for C.A.II are presented in figures 13 and 14 . It is worth to mention that only w/c ratio 0.40 and 0.50 were analyzed, since higher $\mathrm{w} / \mathrm{c}$ ratio led to reliability indexes lower than the target. Consequently, it indicates that these $\mathrm{w} / \mathrm{c}$ ratios should not be used in reinforced concrete applications.

Figure 13 presents the behaviour of the reliability index in function of time for concretes procedures in reinforced concrete structures as function of w/c ratio adopted. For each w/c value adopted for concrete conception, an abacus can be constructed using the probabilistic model. These abacuses allow the choice of an optimum value of concrete cover in order to perform maintenance procedures in fixed time intervals. It is important to stress that these intervals are based on safety criterion. Then, the costs involved in maintenance and repair costs are not considered.

For this proposal, a reference value, named target, of reliability index was chosen, which was assumed as minimum requirement of safety. Then, when the structure has a reliability index lower than the target one, maintenance is required. According [29], the target reliability index expresses the requirements of structural safety, which guarantees acceptable values of structural failure risk considering a given scenario. In this regard, [29] defines a set of values of target reliability index considering failure limit state and serviceability limit state scenarios. The corrosion time initiation is considered as a serviceability limit state scenario. In this study, the loss of reinforcements cross sections have not been considered, which is a failure limit state. Therefore, the target reliability index adopted is 1.30 leading a probability of failure close to $10 \%$. Other values of target reliability index can, evidently, be adopted as function of the structural risk desired.

The analyses in this application were carried out considering the random variables presented in table 2 , as well its statistical proper-

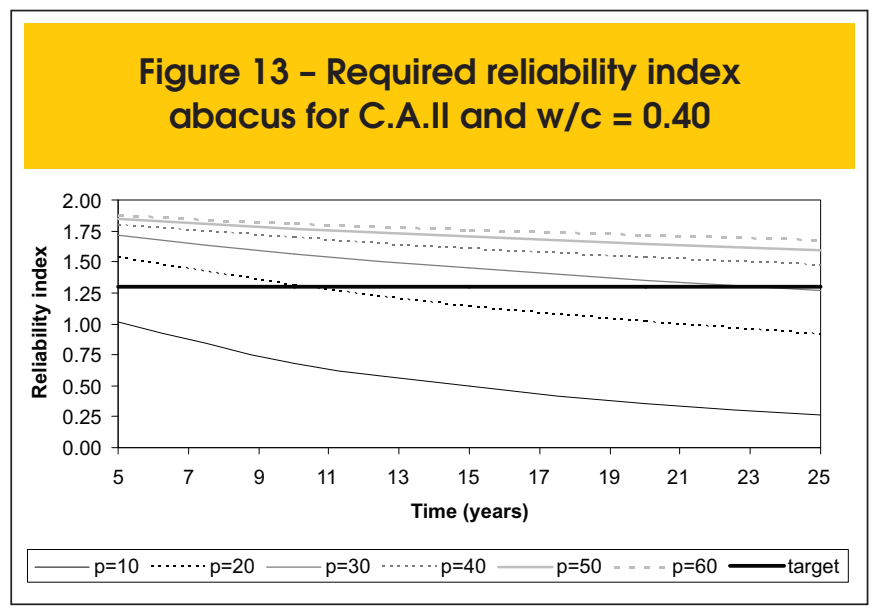

with w/c ratio equal to 0.40 and C.A.II. According these results, cover depth value of $10 \mathrm{~mm}$ is not recommended, because it indicates failure (reliability index lower than the target) even for short time after construction. For cover depth of $20 \mathrm{~mm}$, the maintenance procedures should be performed 10 years after construction. At this time, the structural reliability index is equal to the target. After this time, the structural reliability becomes lower than the target, indicating failure. It is worth to mention that cover depths values bigger than $30 \mathrm{~mm}$ lead maintenance time interval bigger than 25 years. In these cases, the analysts should study the possibility of change of w/c ratio in order to allow, at least, one inspection in the first 25 years of structural life-time.

Similar behaviour can be observed in figure 14, where concretes with w/c 0.50 and C.A. II were considered. In this case, the minimum cover required is $30 \mathrm{~mm}$, which lead to maintenance procedures 8 years after construction. Otherwise, considering cover depth equal to $50 \mathrm{~mm}$, the maintenance procedure should be performed 21 years after construction in order to keep the structural safety at a desired level. Therefore, by changing the cover depth from $30 \mathrm{~mm}$ to $50 \mathrm{~mm}$, or increasing the cover in $20 \mathrm{~mm}$, the maintenance can be performed 13 years later.

On the other hand, considering cover depth of $30 \mathrm{~mm}$, the maintenance time for concretes with $w / c$ ratio 0.40 and 0.50 are 23 and 8 years, respectively, in C.A.II. Then, it can be verified an increment of $187.5 \%$ on the maintenance time interval by slightly

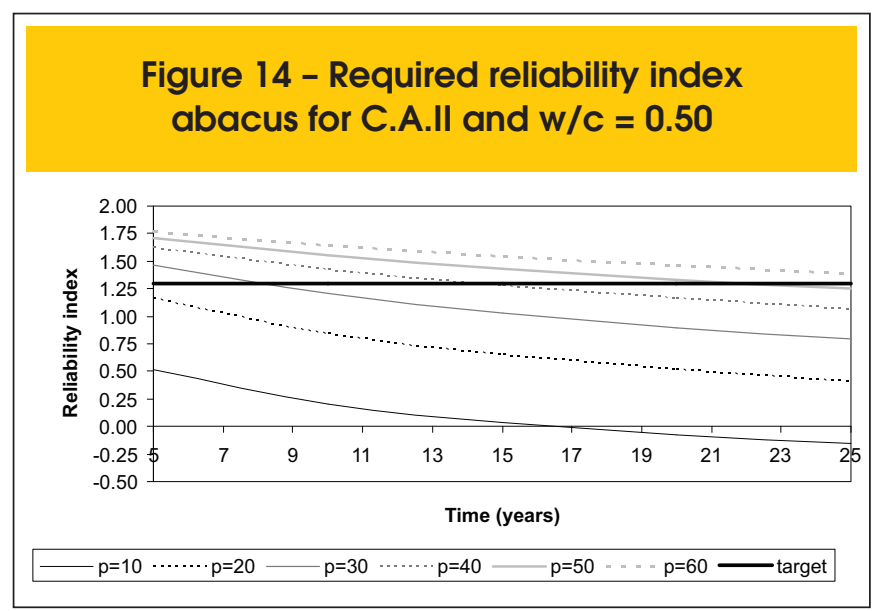




\section{Figure 15 - Required reliability index abacus for C.A.III and $w / c=0.40$}

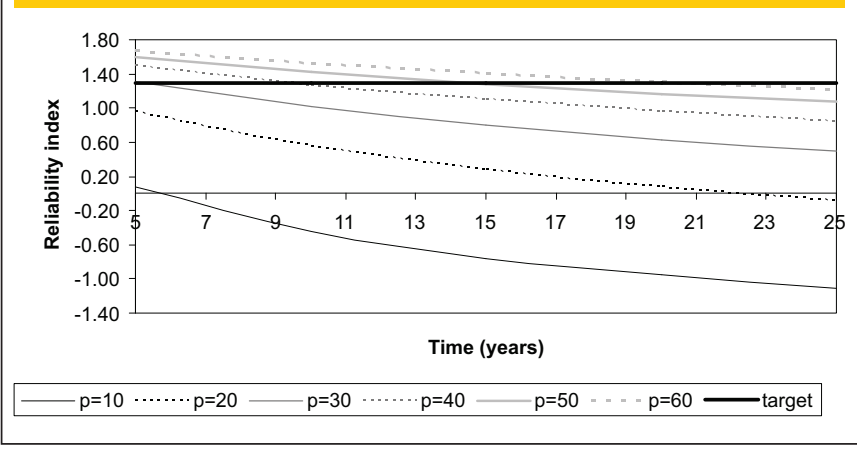

changing the $w / c$ ratio. Moreover, keeping constant the $w / c$ ratio, 0.50 for instance, and changing the cover depth from 30 to $40 \mathrm{~mm}$, the maintenance time are 8 and 14 years, respectively, for C.A.II. Therefore, by changing in $10 \mathrm{~mm}$ the cover thickness, it results an improvement of $75 \%$ on the maintenance time.

The abacuses involving the reliability index in function of $\mathrm{w} / \mathrm{c}$ ratio and cover depth values for category of aggressiveness III are presented in figures 15 and 16 . Considering these two last figures, the same remarks discussed for C.A.II can be done. However, in this case, the intervals of time for maintenance are considerable reduced due the aggressiveness of the environment analyzed, which is higher than the observed for C.A.II.

It is important to emphasize that when the w/c ratio grows, small values of cover depth tend to be prohibitive regarding the corrosion time initiation failure. Moreover, in this case, the time interval for maintenance procedures will be drastically reduced. Therefore, regarding concretes with high values of $\mathrm{w} / \mathrm{c}$ ratio, maintenance procedures in short periods of time and high values of cover depth have to be used in order to prevent reinforcement's corrosion.

Based on the results presented in this application, optimum concrete mixtures and cover depth values can be obtained in order to guarantee the durability of reinforced concrete structures. Moreover, these parameters can be allied to construction, maintenance and reparation costs aiming to determine the global structural cost taking into account the corrosion failure scenario. This type of analysis will be considered by the authors in future works.

\section{Conclusions}

This paper presented a study for probabilistic corrosion initiation in reinforced concrete structures using the coupling among second Fick's diffusion law and reliability algorithms. In this case, the corrosion starts when the chemical protection surrounding the steel bars is loss due chloride ingress. The analyses of probability of corrosion initiation along time were carried out considering two different categories of environment aggressiveness and several combinations of cover depth and concrete properties (w/c ratio). As verified in the results presented, the corrosion initiation depends on several parameters. However, the chloride concentrations at the structural surface and the cover depth values have demonstrated to have major importance on the probabilistic analysis. Equally, the coefficient of diffusion is also important in order to measure the

\section{Figure 16 - Required reliability index abacus for C.A.III and $w / c=0.50$}

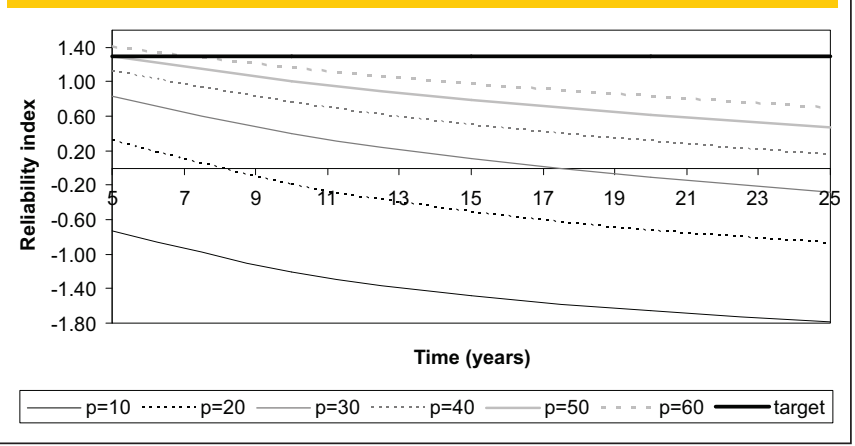

material resistance against the chloride ingress and it can be determinant for choose optimal values of the concrete cover.

According the results achieved in this paper, the durability of reinforced concrete structures has to be associated with more fair values of cover depth, which are, in general, based only on international concrete standard design. This parameter is more realistically evaluated using probabilistic approaches in order to take into account the inherently randomness present on degradation phenomenon, which affect structural durability.

Regarding the choice of optimum values of cover depth, it was observed that this parameter strongly depends on the concrete quality against porosity, which is reflected by w/c ratio, as well as on the period of time attributed for structural interventions for maintenance procedures. Evidently, the determination of optimum combination among concrete material mixture, cover depth value and construction/maintenance/reparation costs is next question to be answered in order to become the structural design more economic, safe and rational. However, the determination of these parameters based only on safety criterion has been shown in this paper. Abacuses were developed in order to allow these analyses, which were constructed using the probabilistic model proposed in this paper.

\section{Acknowledgements}

The authors would like to thank FAPESP - São Paulo Research Foundation for the finantial support and scholarships.

\section{References}

[01] ANGST, U.; ELSENER, B; LARSEN, C. K.; Vennesland, $\varnothing$. Critical chloride content in reinforced concrete - a review, Cement and Concrete Research, 39:1122-1138, 2009.

[02] GUZMÁN, S; GÁLVEZ, J.C; SANCHO, J.M. Cover cracking of reinforced concrete due to rebar corrosion induced by chloride penetration, Cement and Concrete Research, 41:893-902, 2011.

[03] XIANG, T; ZHAO, R. Reliability evaluation of chloride diffusion in fatigue damaged concrete, Engineering Structures. 29:1539-1547, 2007.

[04] SARVESWARAN, V.; ROBERTS, M.B. Reliability 
analysis of deteriorating structures - the experience and needs of practicing engineers, Structural Safety. 21:357-372, 1999.

[05] KONG, J.S.; ABABNEH, A.N.; FRANGOPOL, D.M.; XI, Y.P. Reliability analysis of chloride penetration in saturated concrete, Probabilistic Engineering Mechanics, 17:305-315, 2002.

[06] KIRKPATRICK, T.J; WEYERS, R.E; ANDERSON-COOK, C.M.; SPRINKLE, M. Probabilistic model for the chloride-induced corrosion service life of bridge decks, Cement and Concrete Research, 32:1943-1960, 2002.

[07] JUNG, W.Y.; YOON, Y.S.; SOHN, Y.M. Predicting the remaining service life of land concrete by steel corrosion, Cement and Concrete Research. 33:663-677, 2003.

[08] TUUTTI, K. Corrosion of steel in concrete Swedish, Cement and Concrete Research Institute Stockholm, 1982.

[09] THIRUMALAI, P ; RAVI, R; PARTHIBAN, G.T. Potential monitoring system for corrosion of steel in concrete, Advances in Engineering Software, 37:375-381, 2006

[10] ENRIGHT, M.P.; FRANGOPOL, D.M. Probabilistic analysis of resistance degradation o reinforced concrete bridge beams under corrosion, Engineering Structures. 20:960-971, 1998.

[11] DURACRETE. Statistical quantification of the variables in the limit state functions, The European Union Brite EuRam 3 contract BRPR-CT95-0132, project BE95-1347, report no BE95-1347/R7; May, 2000

[12] VU, K.A.T.; STEWART, M.G. Structural reliability of concrete bridges including improved chloride-induced corrosion models, Structural Safety. 22:313-333, 2000.

[13] BALAJI RAO, K.; ANOOP, M. B.; LAKSHMANAN, N.; GOPALAKRISHNAN, S.; APPA RAO, T. V. S. R. Risk-based remaining life assessment of corrosion affected reinforced concrete structural members, Journal of Structural Engineering, 31: 51-64, 2004.

[14] STEWART, M.G.; ROSOWSKY, D.V. Structural safety and serviceability o concrete bridges subject to corrosion, Journal Infrastructure System. ASCE, 4:146-155, 1998.

[15] ESTES, A.C.; FRANGOPOL, D.M. Updating bridge reliability based on bridge management systems visual inspection results, ASCE Journal of Bridge Engineering. 8:374-382, 2003.

[16] SUO, Q.; STEWART, M.G. Corrosion cracking prediction updating of deteriorating RC structures using inspection information, Reliability Engineering and System Safety. 94:1340-1348, 2009.

[17] CRANK, J. The mathematics of diffusion, $2^{\text {nd }}$ Ed. Clarendon Press, Oxford, London. 414 p, 1975.

[18] DHIR, R.K.; JONES, M.R.; NG, S.L.D. Prediction of total chloride content profile and concentration/ time-dependent diffusion coefficients for concrete, Magazine of Concrete Research, 50:37-48, 1998.

[19] DITLEVSEN, O.; MADSEN, H.O. Structural reliability method, New York: John Wiley and Sons, 1996.

[20] HASOFER, A.M.; LIND, N.C. Exact and invariant second moment code format, Journal of the Engineering Mechanics Division, ASCE. 100 (EM1): 111-121, 1974

[21] LEONEL, E.D; BECK, A.T; VENTURINI, W.S. On the performance of response surface and direct coupling approaches in solution of random crack propagation problems. Structural Safety. 33:261-274, 2011.

[22] LEONEL, E.D; CHATEAUNEUF, A; VENTURINI, W.S. (2012). Probabilistic crack growth analyses using a boundary element model: Applications in linear elastic fracture and fatigue problems, Engineering Analysis with Boundary Elements, 36:944-959, 2012.

[23] LEONEL, E.D; CHATEAUNEUF, A; VENTURINI, W.S; BRESSOLETTE P. Coupled reliability and boundary element model for probabilistic fatigue life assessment in mixed mode crack propagation. International Journal of Fatigue. 32:1823-1834, 2010.

[24] RACKWITZ, R; FIESSLER, B. Structural reliability under combined random load sequences, Computers \& Structures, 9:489-494, 1978.

[25] NOWAK, A.S.; COLLINS, K.R. Reliability of structures, McGraw Hill, Michigan, 2000.

[26] Brazilian Association of Technical Standards. ABNT NBR 6118 - Design of concrete structures - procedures, Rio de Janeiro, 2003.

[27] PAPADAKIS, V.G.; ROUMELIOTIS, A.P.; FARDIS, M.N.; VAGENAS, C.G. Mathematical modeling of chloride effect on concrete durability and protection measures, In Dhir, R.K., Jones, M.R., editors. Concrete repair, rehabilitation and protection. London, E\&FN Spon, 1996.

[28] LEONEL, E.D; VENTURINI, W.S; CHATEAUNEUF, A. A BEM model applied to failure analysis of multi-fractured structures. Engineering Failure Analysis, 18: 1538-1549, 2011.

[29] JCSS - Joint Committee on Structural Safety, 12 ${ }^{\text {th }}, 2001$. "Probabilistic Model Code", 2001. 